\title{
AÇÕES JUDICIAIS, CONTEÚDOS POLÍTICOS: UMA PROPOSTADE ANÁLISE PARA O CASO BRASILEIRO
}

Fabiano Engelmann

\author{
Marcio Camargo Cunha Filho
}

\begin{abstract}
RESUMO
Ações judiciais demandando políticas públicas são recorrentes nas democracias ocidentais. Este artigo pretende analisar a especificidade dos embates em torno deste tema no Brasil a partir da categorização dos significados políticos presentes nos argumentos mobilizados no espaço jurídico. Os dados apresentados foram construídos a partir de uma série de decisões judiciais do Tribunal de Justiça do Estado do Rio Grande do Sul e do Supremo Tribunal Federal em torno das demandas fundadas no "direito à saúde". Os perfis de argumentos presentes nas decisões evidenciam que o ativismo do Judiciário é balizado em concepções jurídicas que opõem a "unidade do Estado" e a "interpretação da Constituição" à dinâmica das administrações públicas. O fenômeno que se pode denominar de "juridicização da política" no Brasil comporta diversos problemas que precisam ser melhor explorados pela ciência política, entre os quais destacamos a emergência de uma "interpretação jurídica" da dinâmica da execução de políticas com forte repercussão pública.
\end{abstract}

PALAVRAS-CHAVE: políticas; Judiciário; Constituição; Brasil.

\section{INTRODUÇÃO ${ }^{1}$}

A base da "juridicização" em uma sociedade remete à clássica noção de Weber sobre a legitimidade do poder político calcada na "crença na racionalidade legal"2, o que pressupõe um consenso generalizado acerca da obediência a normas jurídicas nas diversas esferas sociais e políticas e o reconhecimento da autoridade dos intérpretes das leis, os juristas. Nesse sentido, o fenômeno da "juridicização da política" nas democracias ocidentais contemporâneas comporta diversos problemas a serem explorados pela Ciência Política, perpassados pela emergência de uma "interpretação jurídica" da vida política.

No caso americano, diversas modalidades de advogados mobilizam o espaço legal para promover causas políticas - contra o Estado e contra as empresas privadas - configurando uma categoria de advogados "profissionais das causas coletivas". Esse fenômeno é indicado nos trabalhos de Sarat e Scheingold (1998; 2006) ${ }^{3}$ e McCann (2010), assim como a emergência

\footnotetext{
1 Artigo produzido a partir de pesquisa que conta com apoio da Fundação de Amparo à Pesquisa do Rio Grande do Sul (FAPERGS). Gostaríamos de agradecer aos pareceristas anônimos da Revista de Sociologia e Política.

2 As bases históricas e sócio-políticas dessa noção estão desenvolvidas na sociologia da dominação de Weber (1997).

3 Todas as citações de referências em língua estrangeira foram traduzidas pelos autores.
}

dos tribunais como promotores de "novos direitos" relacionados às mulheres, meio ambiente etc. é abordada no trabalho de Epp (1998). Nos países europeus também são identificadas diversas maneiras de advocacia coletiva, vinculadas à defesa de grupos socialmente excluídos (como os imigrantes) ou grupos de interesse, como destacam a coletânea de Commaille e Kaluzynski (2007) e Israel (2009).

Rosenberg (2008) destaca que três fatores impedem um efetivo impacto das Cortes no policy making: a natureza limitada dos direitos constitucionais, a ausência de uma efetiva independência judicial, e, por fim, as restritas prerrogativas coercitivas do poder Judiciário. Na visão de Rosenberg (idem), esses três obstáculos raramente são superados, e o resultado é que as decisões judiciais norte-americanas dificilmente produzem mudanças relevantes nas esferas econômica, política ou social.

Em outro sentido, Epp (1998) argumenta que o poder Judiciário adquirirá a capacidade de intervir em questões políticas proeminentes desde que esteja inserido em uma sociedade dotada do que chama de support structure, ou seja, uma sociedade que conte com associações civis bem organizadas, ideologicamente definidas e contando com uma assessoria jurídica estruturada. $\mathrm{O}$ autor argumenta que, nos Estados Unidos, essas entidades foram cruciais na luta pelo reconhecimento judicial de importantes direitos civis, especialmente nos casos do fim da 
segregação entre negros e brancos e, também, no caso dos direitos feministas. Epp (idem) contrasta o caso americano ao da Índia, onde os profissionais jurídicos atuam de maneira mais desorganizada e individualista, ocorrendo uma efetiva rights revolution, apesar das tentativas da Suprema Corte indiana nesse sentido.

Outra espécie de mobilização que remete a uma "interpretação jurídica" das práticas políticas pode ser encontrada nas ações em torno do "combate à corrupção". Em especial na França e Itália na década de 1990, destaca-se um ativismo baseado na "moralização das instituições políticas". São processos judiciais propostos contra empresários e parlamentares acusados de crimes financeiros ou mesmo envolvidos com a máfia, como demonstram os trabalhos de Roussel (2002) e Garraud (2001), para a França, e Briquet (2001), para a Itália. Essa forma de ativismo judicial contra a "política tradicional" extrapola o mero controle da legalidade de atos ilícitos dos agentes públicos ou privados e amplia-se, em diversos casos, para uma cruzada pela "moralização da política" incluindo o apoio de Organizações Não Governamentais (ONGs), imprensa e a mobilização da "opinião pública"4.

Tal fenômeno demanda uma compreensão mais ampla da construção da legitimidade do poder judicial frente ao universo da política. Em especial, estudos mais aprofundados sobre as concepções morais e as noções de atividade política que permeiam a ação dos juristas a partir de um "poder neutro" contra os "políticos tradicionais" vinculados à representação de interesses.

A hipótese da existência de concepções de ação política próprias dos juristas posicionados em um universo relativamente autônomo em relação ao vivier dos políticos (partidos, poder Legislativo, poder Executivo, por exemplo) também é explorada por Roussel (2002), ao estudar a ação dos magistrados em diversos escândalos políticos ocorridos na França

\footnotetext{
4 Jean-Louis Briquet na "Introdução" à coletânea Juger la politique, publicada em 2001 (BRIQUET \& GARRAUD, 2001), utiliza a noção de "empresa de moralização política" ao abordar o imbricamento entre o jornalismo político, a magistratura de investigação e as ONGs de transparência política. Para o autor, a "interpretação jurídica" é instrumentalizada também pela lógica da produção do "escândalo político" própria ao campo do jornalismo político. O fenômeno extrapola, portanto, uma mera questão de punição de ilegalidades cometidas por políticos.
}

ao longo da década de 1990. A adesão a um sentido compartilhado de "moralidade política" mobiliza conceitos e definiçõos presentes em doutrinas jurídicas sobre o Estado. A autonomização dos magistrados recrutados por concurso e o enfraquecimento de laços de solidariedade com políticos locais são apontados por Roussel - para o caso francês - como variáveis fundamentais na compreensão da forte intervenção dos magistrados na esfera política.

O trabalho comparativo de Shapiro e Sweet (2002) sobre os processos de judicialização de políticas nos Estados Unidos e países da Europa indicam que este processo é um fenômeno empiricamente verificável, não sendo permanente nem uniforme, tampouco se esgotando no ativismo de minorias políticas com menor força no poder Legislativo. Conforme os autores, na França, a "privatização", as "políticas de comunicação social", a "legislação criminal" e a "legislação eleitoral" são exemplos de temas altamente judicializados. No caso da Alemanha, destacam-se a "educação", a "justiça criminal" e o "financiamento de campanhas eleitorais". Aqui se pode contrapor o caso brasileiro, no qual o ativismo judicial em torno de políticas sociais aparece com grande evidência no caso das políticas de saúde, como apontam, entre tantos trabalhos que retratam o fenômeno da "judicialização da saúde", os de Souza Neto e Sarmento (2008), Barroso (2009), Biehl (2009) e Menicucci e Machado (2010).

O presente trabalho enfoca uma amostra de ações judiciais propostas contra municípios gaúchos e contra o próprio estado do Rio Grande do Sul, analisadas à luz da especificidade da "judicialização das políticas" no caso brasileiro. Tem-se como uma hipótese central que a matriz doutrinária e as representações do sentido da atividade política que fundamentam as ações judiciais opõem a "visão dos juristas", imbuída de uma espécie de "guarda do universal", à “visão do profissional da política", vinculada predominantemente às lógicas específicas da atividade de representação e reprodução eleitoral.

A recomposição do contexto das ações judiciais, os temas envolvidos e a mediação do poder Judiciário ajudam a compreender a maior ou menor autonomia e "poder de intervenção" dos juristas na esfera dos "políticos profissionais". Assim, espera-se contribuir também para o avanço de uma Sociologia Política das instituições judiciais, nos termos definidos por Commaille, Dumoulin e Robert (2000), Commaille e Duran (2009) e Vauchez (2009), somando na compreensão das condições de legitimação das concepções políticas dos juristas e da porosidade entre a esfera judicial e política. 


\section{DOUTRINAS JURÍDICAS E "JUDICIALIZAÇÃO” DE POLÍTICAS}

Embora a "legitimidade de agir" dos agentes, promotores, defensores públicos e advogados esteja calcada na idéia da "efetivação de direitos fundamentais" "previstos na Constituição" e em leis específicas, a construção de doutrinas presente nas publicações jurídicas contribui para dar sentido e para delimitar o espaço possível dessa intervenção, no sentido comum das práticas jurídicas. $\mathrm{O}$ estudo das "doutrinas jurídicas" - do ponto de vista das Ciências Sociais - implica romper com a representação ideológica que os "juristas doutrinadores" constroem a seu respeito. Conforme Dezalay (1993), o estudo da legitimidade da produção doutrinal tem como ponto de partida a ruptura com a idéia de que ela constitui-se em uma "construção científica tendo por fim o aperfeiçoamento do Direito fora dos constrangimentos sociais" (DEZALAY, 1989, p. 232). Embora, no caso brasileiro, a produção da doutrina não ocorra em um espaço universitário autônomo e em oposição ao universo dos "práticos do direito"5, a grande expansão dos programas de pós-graduação em Direito na década de 1990 indica uma significativa profissionalização acadêmica da produção doutrinal brasileira ${ }^{6}$.

A construção de uma abordagem jurídica capaz de legitimar a intervenção judicial na condução de políticas envolve uma agenda doutrinária, além das disposições dos agentes judiciais de posicionarem-se no espaço de poder. Conforme Barcellos (2008) há três "axiomas" incorporados à prática jurídica no Brasil que são praticamente consensuais entre os juristas. O primeiro prega que "as disposições constitucionais, tenham elas a natureza de regra ou de princípio, são dotadas de normatividade" e logo produzem efeitos no "mundo dos fatos", assim como "gozam de superioridade hierárquica no âmbito do sistema jurídico" (idem, p.115).

O segundo axioma referido pela autora mobiliza o argumento do "status diferenciado" dos direitos fundamentais no âmbito do sistema constitucional. Nesse sentido, "o Estado e o Direito existem para proteger e promover os direitos fundamentais, de modo que tais estruturas devem ser compreendidas e

\footnotetext{
5 Para maior detalhamento sobre a configuração da produção doutrinal e as oposições, na França, entre "professores de Direito e doutrinadores", de um lado, e "práticos", de outro, ver Chevalier (1993).

6 Sobre a expansão dos programas de pós-graduação em Direito e a produção de doutrinas jurídicas, ver Engelmann (2006; 2008).
}

interpretadas tendo em conta essa diretriz" (ibidem). Por fim, o terceiro "axioma" concerne à subordinação dos poderes públicos à Constituição. Conforme a autora, embora Constituição não deva "sufocar" a deliberação majoritária, uma das funções de um texto constitucional é vincular os agentes políticos à promoção dos direitos fundamentais.

O exame mais sistemático dos livros de doutrina jurídica que aborda a "judicialização" de políticas permite um inventário dos principais perfis de argumentos mobilizados, assim como a construção de categorias sobre os conteúdos que dividem a discussão dos juristas sobre essa questão. Por exemplo, uma primeira oposição - que não será aprofundada neste artigo - indicada por trajetos profissionais encontrada na amostra de autores de livros de doutrina sobre o "controle jurisdicional de políticas" distingue doutrinadores que exercem a função de promotores de justiça, cumulativamente com a atividade de magistério, da produção intelectual de procuradores de estado e do município. Os promotores tendem a posicionar-se favoravelmente ao ativismo judicial nas questões sociais, e os procuradores do estado e dos municípios tendem a ser contrários, o que evidentemente coaduna-se com as posições ocupadas por esses agentes no espaço das práticas judiciais. Embora essas indicações demandem uma pesquisa à parte, elas contribuem para mostrar a imbricação entre o espaço da produção das doutrinas e as oposições que se firmam no campo das práticas judiciais.

Os argumentos mais recorrentes mobilizados pelos autores que se posicionam "contra" a judicialização de políticas evocam a "separação de poderes", ressaltando uma "indevida ingerência" do poder Judiciário em matérias de competência do poder Executivo, assim como a necessidade de "racionalidade da administração", que envolve a autonomia das administrações em definir critérios para a execução de políticas. Ainda se pode adicionar a esse argumentos outros conteúdos que evocam sentidos "sociais", como a idéia de que o acesso ao poder Judiciário é restrito a segmentos mais abastados da sociedade. Da mesma forma, verifica-se a presença dos argumentos baseados em princípios teóricos como a doutrina alemã do "princípio da reserva do possível" que prega que somente parte do orçamento público pode ser "disputável" em demandas judiciais. O quadro a seguir traz exemplos que ilustram o núcleo discursivo desses argumentos construídos a partir do exame de publicações jurídicas. 


\section{QUADRO 1 -ARGUMENTOS CONTRÁRIOS À JUDICIALIZAÇÃO}

\begin{tabular}{|c|c|}
\hline Perfil do argumento & Exemplos representativos \\
\hline $\begin{array}{l}\text { Princípio da separação dos } \\
\text { poderes e legitimidade políti- } \\
\text { ca dos poderes Executivo e } \\
\text { Legislativo para definirem } \\
\text { políticas }\end{array}$ & $\begin{array}{l}\text { Esse argumento aduz, em linhas gerais, que a política de saúde pública, } \\
\text { devido à sua relevância e ao seu profundo impacto orçamentário, deve ser } \\
\text { elaborada e executada pelos órgãos representativos, ou seja, pelos poderes } \\
\text { Executivo e Legislativo. Assim sendo, os juízes não teriam a legitimidade } \\
\text { conferida aos poderes eleitos para promover essa alocação de recursos. } \\
\text { Defensor desse argumento: Beserra (2005). }\end{array}$ \\
\hline
\end{tabular}

\begin{tabular}{|c|c|}
\hline $\begin{array}{l}\text { Racionalização da adminis- } \\
\text { tração pública }\end{array}$ & $\begin{array}{l}\text { Essa linha de crítica à judicialização da saúde afirma que o poder Executivo e } \\
\text { o poder Legislativo estão em melhores condições políticas de definir e } \\
\text { implementar a política de saúde pública. Isso porque os legisladores, assim } \\
\text { como os integrantes do Ministério da Saúde, contam com ampla equipe de } \\
\text { técnicos e assessores, os quais podem Ihes fornecer as informações } \\
\text { necessárias para a melhor distribuição de recursos. Já os juízes, que se } \\
\text { ocupam apenas de lides individuais, não têm uma dimensão do todo, ou } \\
\text { seja, não estão capacitados, devido à sua posição no espaço político, a } \\
\text { promover uma política de distribuição de recursos. Defensores desse } \\
\text { argumento: Gouvêa (2003); Barcellos (2006), entre outros. }\end{array}$ \\
\hline $\begin{array}{l}\text { Argumento do "tiro pela } \\
\text { culatra" }\end{array}$ & $\begin{array}{l}\text { Os juízes, ao conceder medicamentos ou tratamentos médicos gratuitos aos } \\
\text { que os pleiteiam judicialmente, iludem-se ao pensar que estão atuando no } \\
\text { sentido de distribuir recursos aos mais necessitados e de reduzir as } \\
\text { desigualdades sociais. Nesses casos, o poder Judiciário estaria, na verdade, } \\
\text { aumentando estas desigualdades, pois não estaria concedendo recursos } \\
\text { aos menos favorecidos, mas, sim, àqueles que possuem o capital } \\
\text { socioeconômico para procurar advogados e reivindicar seus direitos frente } \\
\text { ao poder Judiciário. Assim, investimentos públicos estariam sendo desviados } \\
\text { dos realmente desprovidos de quaisquer recursos em favor integrantes da } \\
\text { classe média organizada. Defensores desse argumento: Barroso (2009); } \\
\text { Tavares (2002); Silva e Terrazas (2011). }\end{array}$ \\
\hline $\begin{array}{l}\text { Argumento da reserva do } \\
\text { possível no orçamento públi- } \\
\text { co }\end{array}$ & $\begin{array}{l}\text { O argumento da reserva do possível é a antítese do aforisma popular segundo } \\
\text { o qual "a saúde não tem preço." Esse argumento invoca a necessitada de } \\
\text { enfrentar o trade off entre eficiência e distribuição, pois, se o poder Judiciário } \\
\text { tentar resolver todos os problema de saúde pública, o Estado iria à falência e } \\
\text { deixaria de investir em outras áreas consideradas relevantes, como educação, } \\
\text { segurança e lazer. Defensores desse argumento: Dworkin (2005); Nunes } \\
\text { Júnior (2009). }\end{array}$ \\
\hline $\begin{array}{l}\text { Argumento da isonomia/ } \\
\text { equidade }\end{array}$ & $\begin{array}{l}\text { Essa concepção defende que todos os cidadãos devem ser tratados } \\
\text { igualmente, o que significa tratar a todos com igualdade de respeito e de } \\
\text { consideração. Segundo os que defendem esta linha, o poder Judiciário } \\
\text { brasileiro rompe com esse princípio, pois, ao tentar dar tudo a todos, acaba } \\
\text { dando tudo a alguns e nada a outros. Defensores desse argumento: Barzotto } \\
\text { (2003); Ferraz e Vieira (2009). }\end{array}$ \\
\hline
\end{tabular}

FONTE: Foram catalogados e analisados 30 trabalhos de doutrina jurídica, incluídos nas referências bibliográficas ao final deste artigo.

Já os argumentos favoráveis à “judicialização" de políticas baseiam-se principalmente em "princípios gerais" e em um movimento doutrinário que atribui aos juristas, como intérpretes da Constituição, um grande poder de agenda política. Entre os princípios, destaca-se a noção de "dignidade da pessoa humana" que se superporia em diversos contextos à escassez orçamentária, por exemplo. A amplitude e pluralidade de sentidos dessa noção legitima um grande poder aos intérpretes da lei que aparecem não somente como guardiões de normas constitucionais e do rule of law, mas como guardas de um sentido moral da política em contrapartida ao que seria "menor", a implementação de políticas com todas as questões financeiras, políticas e administrativas implicadas.

Nesse contexto argumentativo, destaca-se a doutrina do "neoconstitucionalismo", que contempla a idéia de que das constituições derivam direitos que não são apenas "programas" ou projetos que orientariam a execução de políticas pelas administrações, mas “direitos” exigíveis judicialmente. 


\section{QUADRO 2 -ARGUMENTOS FAVORÁVEIS À JUDICIALIZAÇÃO DE POLÍTICAS PÚBLICAS}

\begin{tabular}{|c|c|}
\hline $\begin{array}{l}\text { Princípio moral - dignidade } \\
\text { da pessoa humana }\end{array}$ & $\begin{array}{l}\text { Esse argumento coloca o princípio da dignidade da pessoa humana como } \\
\text { um meta-princípio absoluto, acima, portanto, de quaisquer considerações } \\
\text { acerca da ordem econômica ou da eficiência. Sendo assim, ocorrendo conflito } \\
\text { de interesses entre o direito à saúde de um cidadão e razões de ordem } \\
\text { financeira do Estado, deve a lide ser resolvida, inexoravelmente, em favor do } \\
\text { primeiro. Defensores desse argumento: diversos ministros do STF, em } \\
\text { especial Celso de Melo (vide Pet. } 1246 \text {, voto do Min. Celso de Mello, Pet. } 1246 \text {, } \\
\text { j. 18.set.2002). }\end{array}$ \\
\hline $\begin{array}{l}\text { Argumento nacionalista - } \\
\text { contra a "importação" da dou- } \\
\text { trina da reserva do possível. }\end{array}$ & $\begin{array}{l}\text { Os defensores dessa tese aduzem que o argumento da reserva do possível, } \\
\text { que teve origem em uma decisão do Tribunal Constitucional alemão, } \\
\text { simplesmente não se aplica ao Direito brasileiro. É que a Constituição } \\
\text { brasileira, ao contrário da alemã, possui densa eficácia normativa, e cria } \\
\text { obrigações específicas ao Estado, às quais correspondem direitos subjetivos } \\
\text { dos cidadãos. Sendo assim, não é possível que os administrados restrinjam } \\
\text { a aplicabilidade daquilo que a Constituição determinou. Defensor desse } \\
\text { argumento: Nunes Júnior (2009). }\end{array}$ \\
\hline $\begin{array}{l}\text { Neoconstitucionalismo - da } \\
\text { Constituição depreendem-se } \\
\text { direitos subjetivos, exigíveis } \\
\text { judicialmente. }\end{array}$ & $\begin{array}{l}\text { O neoconstitucionalismo propõe que direitos e obrigações podem ser extraídos } \\
\text { diretamente da Constituição nacional, sem intermédio de diplomas legislativos } \\
\text { secundários. Assim, quando a Constituição brasileira afirma que "a saúde é } \\
\text { obrigação de todos e dever do Estado", gera-se, conforme a interpretação } \\
\text { neoconstitucionalista, um direito subjetivo por parte dos cidadãos, sem que } \\
\text { seja necessário editar uma lei para tornar esse direito exigível perante os } \\
\text { tribunais. Defensores desse argumento: Frischeisen (2000); Zagrebelsky }\end{array}$ \\
\hline $\begin{array}{l}\text { Argumento da ponderação } \\
\text { de princípios. }\end{array}$ & $\begin{array}{l}\text { Segundo esse argumento, as lides judiciais em que se requer a concessão } \\
\text { gratuita de medicamentos ou de tratamento médico envolve uma ponderação } \\
\text { de dois princípios relevantes: de um lado, o bem-estar e a saúde dos cidadãos } \\
\text { e, de outro, as prerrogativas orçamentárias do Estado. Constatando o embate } \\
\text { entre princípios nesses termos, boa parte da literatura especializada tem } \\
\text { afirmado que, nesses casos, deve sempre prevalecer o direito à vida e à } \\
\text { saúde do cidadão - ambos mais importantes do que os "interesses financeiros } \\
\text { secundários do Estado". }\end{array}$ \\
\hline
\end{tabular}

FONTE: O autor, segundo bibliografia indicada.

\section{AÇÕES JUDICIAIS E DEMANDAS POR POLÍ- TICAS: O CASO DO TRIBUNAL DE JUSTIÇA NO RIO GRANDE DO SUL}

A análise de uma amostra de decisões judiciais de segundo grau que têm por foco demandas por políticas - majoritariamente políticas de saúde - fornece importantes indicações sobre o fenômeno de judicialização de políticas no Brasil. Também é possível analisar a partir da leitura das decisões e dos principais argumentos esboçados a "força" das teorias e construções doutrinárias divulgadas nas mais diversas espécies de publicações de Direito.

Os dados apresentados foram montados a partir de um banco construído para a década de 2000, com ações propostas contra municípios e contra o estado do Rio Grande do Sul, tendo por foco a execução de políticas majoritariamente de serviços de saúde. A amostra foi definida a partir da consulta à base de informações sobre os acórdãos de decisões do Tribunal de Justiça do Estado do Rio Grande do Sul, tendo foco ações com julgamento final entre 2 de janeiro de 2000 e 2 de janeiro de 2011. O critério de busca na base do Tribunal foi por palavras-chave, utilizando-se o termo "reserva do possível - políticas públicas" e não se fazendo restrições para o tipo de ação ou proponente. A partir desses critérios chegouse a um $\mathrm{N}$ de 783 .

Nota-se que esses critérios foram estabelecidos em função das limitações do sistema de busca existente e subsidiaram uma primeira exploração. Optou-se por não cortar por determinada modalidade de ações judiciais para ter-se uma caracterização do perfil de demandas. A adição da expressão "reserva do possível" com o termo "políticas públicas" deve-se à discussão doutrinária sobre o "controle jurisdicional de políticas públicas"7 com base em normas constitucionais que se referem aos limites orçamentários dos municípios.

\footnotetext{
7 Ver Sarlet e Timm (2008) e Biehl (2009).
} 
Essa expressão contribui para restringir o quantitativo de ações, pois com a expressão "políticas públicas", uma primeira exploração indicou que o número de acórdãos apresentava grande dispersão em relação à problemática do trabalho tornando inviável a coleta das informações.

O quantitativo foi organizado a partir das seguintes informações: (a) número do processo; (b) parte requerente; (c) parte requerida; (d) data de julgamento final; (e) tema; (f) nome do município; (g) mérito do julgamento final e (h) conteúdo da decisão.

III.1. Perfil dos argumentos mobilizados pelos desembargadores nas decisões judiciais

As decisões judiciais analisadas foram proferidas em ações de recurso de sentenças de juízes de primeiro grau. Nesse sentido, os magistrados de segundo grau reiteram argumentos mobilizados por julgadores de primeiro grau, assim como fixam referências para decisões futuras.

Para a catalogação dos perfis das decisões foram analisados os núcleos argumentativos que indicavam a base de legitimidade para as decisões presentes nos acórdãos judiciais. Foram construídas seis grandes categorias de argumentos que podem ser caracterizados como predominantemente "políticos", em relação a argumentos de natureza técnica-processual. Nesse sentido, foram excluídos os casos de decisões que discutiam questões meramente processuais, chegandose ao $\mathrm{N}$ de 771 .

A primeira categoria de argumentos ("argumento 1"), compreende decisões judiciais em que aparecem contrapostas a autoridade do poder Judiciário à do poder Executivo na organização da gestão pública. Pode-se mencionar como ilustrativos o uso, por parte dos juízes, do instrumento do bloqueio de contas de prefeituras e do Estado. Da mesma forma, a superposição entre a demanda judicial e a demanda administrativa dirigida diretamente à prefeitura ou órgão da administração pública estadual.

Uma segunda categoria que aparece com freqüência alta ("argumento 2") agrupa decisões em que o
Tribunal define o sentido do princípio da separação e divisão de poderes. O princípio da divisão de poderes é invocado principalmente pelos procuradores municipais e estaduais na defesa do poder Executivo contra as ações judiciais. As decisões indicam que o Tribunal superpõe o "direito fundamental à saúde" ao princípio da divisão e separação dos poderes.

A terceira categoria de argumentos concerne à atuação do Tribunal como "guardião da Constituição" ("argumento 3"). Nesse conjunto, as decisões apontam especificamente o caráter "constitucional" do direito à saúde, aparecendo os poderes executivos municipal e estadual como descumpridores da Constituição ou evocando legislações que são menores do que a Constituição.

Um quarto conjunto, ("argumento 4"), centra-se na definição da "unidade do Estado" no adimplemento de políticas públicas derivadas de direitos constitucionais. Mais uma vez, o Tribunal define o sentido de princípios de funcionamento do Estado, assim como no caso da discussão da separação de poderes. Nesse caso, trata-se da superposição de uma noção abstrata de "Estado uno" ao princípio da federação que envolve um conjunto de legislações que aponta para repartições de competências e divisão de na execução de políticas.

As decisões agrupadas em uma quinta categoria, compondo o "argumento 5", superpõem a idéia abstrata de "direito" ou "efetividade do direito", à organização da gestão pública, especialmente da gestão orçamentária. Aqui fica bastante clara uma intervenção específica, característica do poder judicial que intervém "em nome do Direito" versus o poder Executivo que constrói argumentos mobilizando expertises advindas da macroeconomia, gestão financeira etc.

Finalmente, um último conjunto de decisões, "argumento 6", que aparece com menor freqüência, mas tem representatividade, diz respeito ao predomínio nas decisões de um juízo moral dos magistrados para com os ocupantes de cargos do poder Executivo. 
QUADRO 3 - PERFIL DAS DECISÕES E ARGUMENTOS POLÍTICOS MOBILIZADOS

\begin{tabular}{|c|c|c|c|}
\hline Categoria de argumento & Freq. & $\%$ & Exemplos \\
\hline $\begin{array}{l}\text { Tribunal opõe autoridade do } \\
\text { poder Judiciário à autoridade } \\
\text { do Executivo na organização da } \\
\text { gestão pública }\end{array}$ & 191 & 25,77 & $\begin{array}{l}\text { "A orientação dessa Corte é tranqüila no sentido da } \\
\text { viabilidade de deferir-se o bloqueio de valores do Estado } \\
\text { para aparelhar de forma mais efetiva o direto à saúde"."O } \\
\text { pedido administrativo apesar de ser um expediente útil } \\
\text { ao ente público e aos próprios cidadãos é uma } \\
\text { formalidade burocrática e sua não observância não pode } \\
\text { ser óbice a impedir o requerimento judicial de } \\
\text { fornecimento do medicamento". }\end{array}$ \\
\hline $\begin{array}{l}\text { Tribunal interpreta sentido do } \\
\text { princípio da divisão dos } \\
\text { poderes }\end{array}$ & 183 & 23,73 & $\begin{array}{l}\text { Condenação dos entes estatais ao atendimento de direito } \\
\text { fundamental à saúde não fere o princípio de divisão dos } \\
\text { poderes. }\end{array}$ \\
\hline $\begin{array}{l}\text { Tribunal guardião da Constitui- } \\
\text { ção }\end{array}$ & 128 & 16,60 & Acesso à saúde é direito constitucional. \\
\hline $\begin{array}{l}\text { Unidade do "Estado" para ga- } \\
\text { rantir direito fundamental su- } \\
\text { perpõem-se a princípio federa- } \\
\text { tivo }\end{array}$ & 128 & 16,60 & $\begin{array}{l}\text { Entes estatais são solidariamente responsáveis pelo } \\
\text { adimplemento dos direitos fundamentais. }\end{array}$ \\
\hline $\begin{array}{l}\text { Efetividade do Direito é superior } \\
\text { à gestão orçamentária e dis- } \\
\text { cussão doutrinária da "reserva } \\
\text { do possível" }\end{array}$ & 107 & 13,87 & $\begin{array}{l}\text { O poder Judiciário não é insensível aos graves e agudos } \\
\text { problemas financeiros por que passam os entes } \\
\text { federativos. Entretanto, ao poder Judiciário cabe dar } \\
\text { efetividade à lei. }\end{array}$ \\
\hline $\begin{array}{l}\text { Tribunal julga moralmente o } \\
\text { poder Executivo }\end{array}$ & 34 & 4,40 & $\begin{array}{l}\text { Falta de previsão orçamentária do Estado para efetivar o } \\
\text { direito à saúde é descaso do administrador com a } \\
\text { população e a ordem constitucional Os maus } \\
\text { antecedentes do Poder Público em relação ao dever de } \\
\text { prestar assistência à saúde, por si só afirmam presunção } \\
\left.\text { de interesse processual (CPC, art. } 3^{\circ}\right) \text {, isto é, } \\
\text { necessidade de intervenção poder do Judiciário. }\end{array}$ \\
\hline
\end{tabular}

FONTE: Banco de dados de acórdãos judiciais do Projeto.

\section{O SUPREMO TRIBUNAL FEDERAL E A JUDI- CIALIZAÇÃO DA SAÚDE}

Nesta seção, é exposta uma série de julgamentos representativos do STF em matéria de efetivação do direito à saúde. Não se tem a pretensão de analisar todas as decisões proferidas pela Corte na última década, mas tão somente alguns dos julgamentos mais citados e mais discutidos pela literatura jurídica especializada, portanto legitimados no campo jurídico.

As conclusões aqui delineadas tiveram por base uma pesquisa quantitativa no sítio eletrônico do STF, tendo por eixo as políticas de saúde. Utilizou-se, como critério de busca, as palavras-chave "medicamento", "fornecimento" e "gratuito", chegando-se a um número de aproximadamente 30 decisões, sendo que a mais antiga destas foi proferida no início da década de 2000, ao passo que a mais recente foi proferida em 2011. Ainda que se admita que a utilização de outras palavras-chave como referência de busca traria resultados distintos, acredita-se que é possível afirmar que a amostra colhida para o presente trabalho é representativa da postura do STF. Isso porque foi possível encontrar um banco de dados amplo tanto do ponto de vista temporal (aproximadamente dez anos), quanto do ponto de vista da diversidade de ministros relatores (dentre os acórdãos analisados neste trabalho, aparecem uma ampla gama de ministros relatores, o que denota que a pesquisa não ficou enviesada, no sentido de colher a postura de apenas um ou alguns poucos julgadores).

Conforme se adiantou, a controvérsia que opõe o juristas nas ações que lidam com a presente temática é bastante clara: deve o Estado fornecer gratuitamente remédios ou tratamentos médicos a cidadãos que não possuem recursos financeiros para adquiri-los?

O STF começou a tratar da questão já na década de 1990, sempre em recursos oriundos do Rio Grande do Sul, estado em que primeiro surgiram disputas judiciais envolvendo o direito à saúde. Àquela época, as ações versavam quase que exclusivamente acerca 
do fornecimento de medicamentos relacionados ao combate do vírus HIV. Frente ao número ainda relativamente baixo de demandas desse tipo, não aparecem, nas primeiras decisões da Corte, as mesmas categorias de argumentos que fundamentam decisões posteriores (calcadas no desenvolvimento de doutrinas mais sistemáticas). A Ementa de decisão de 1999, a seguir, é ilustrativa nesse sentido: "EMENTA [...] SAÚDE - PROMOÇÃO - MEDICAMENTOS. O preceito do artigo 196 da Constituição Federal assegura aos necessitados o fornecimento, pelo Estado, dos medicamentos indispensáveis ao restabelecimento da saúde, especialmente quando em jogo doença contagiosa como é a Síndrome da Imunodeficiência Adquirida" (BRASIL, 1999).

Como se vê, o tema era tratado pelo Supremo como uma questão de mera subsunção de dispositivo constitucional: uma vez que o art. 196 menciona que a saúde é obrigação do Estado, uma pessoa enferma necessariamente tem o direito de obter todo o tratamento médico de que necessite.

Em outros julgamentos realizados no mesmo período, o STF decidiu de maneira bastante similar. Pode-se citar, como exemplos, os seguintes processos: Agravo 232469-RS, Relator Min. Marco Aurélio; Agravo 236644-RS, Relator Min. Maurício Correa; Recurso Extraordinário 273-042-RS, Rel. Min. Carlos Velloso.

A partir do início da década de 2000 , o volume de processos envolvendo a temática do direito à saúde cresce, e as decisões no STF tendem a aparecer de maneira mais fundamentada em doutrinas constitucionais. É o que ocorre no Agravo Regimental no Recurso Extraordinário 271286 AgR/RS, Relator Min. Celso de Mello, julgado em 12 de setembro de 2000: "EMENTA: PACIENTE COM HIV/AIDS PESSOA DESTITUÍDA DE RECURSOS FINANCEIROS - DIREITO À VIDA E À SAÚDE FORNECIMENTO GRATUITO DE MEDICAMENTOS DEVER CONSTITUCIONAL DO PODER PÚBLICO (CF, ARTS. $5^{\circ}$, CAPUT, E 196) - PRECEDENTES (STF) - RECURSO DE AGRAVO IMPROVIDO. O DIREITO À SAÚDE REPRESENTA CONSEQÜÊNCIA CONSTITUCIONAL INDISSOCIÁVEL DO DIREITO À VIDA. O direito público subjetivo à saúde representa prerrogativa jurídica indisponível assegurada à generalidade das pessoas pela própria Constituição da República (art. 196). Traduz bem jurídico constitucionalmente tutelado, por cuja integridade deve velar, de maneira responsável, o Poder Público, a quem incumbe formular - e implementarpolíticas sociais e econômicas idôneas que visem a garantir, aos cidadãos, inclusive àqueles portadores do vírus HIV, o acesso universal e igualitário à assistência farmacêutica e médico-hospitalar. O direito à saúde - além de qualificar-se como direito fundamental que assiste a todas as pessoas representa consequência constitucional indissociável do direito à vida. O Poder Público, qualquer que seja a esfera institucional de sua atuação no plano da organização federativa brasileira, não pode mostrar-se indiferente ao problema da saúde da população, sob pena de incidir, ainda que por censurável omissão, em grave comportamento inconstitucional. A INTERPRETAÇÃO DA NORMA PROGRAMÁTICA NÃO PODE TRANSFORMÁ- LA EM PROMESSA CONSTITUCIONAL INCONSE-QÜENTE. O caráter programático da regra inscrita no art. 196 da Carta Política - que tem por destinatários todos os entes políticos que compõem, no plano institucional, a organização federativa do Estado brasileiro - não pode converter-se em promessa constitucional inconseqüente, sob pena de o Poder Público, fraudando justas expectativas nele depositadas pela coletividade, substituir, de maneira ilegítima, o cumprimento de seu impostergável dever, por um gesto irresponsável de infidelidade governamental ao que determina a própria Lei Fundamental do Estado. DISTRIBUIÇÃO GRATUITA DE MEDICAMEN-TOS A PESSOAS CARENTES. O reconhecimento judicial da validade jurídica de programas de distribuição gratuita de medicamentos a pessoas carentes, inclusive àquelas portadoras do vírus HIV/AIDS, dá efetividade a preceitos fundamentais da Constituição da República (arts. $5^{\circ}$, caput, e 196) e representa, na concreção do seu alcance, um gesto reverente e solidário de apreço à vida e à saúde das pessoas, especialmente daquelas que nada têm e nada possuem, a não ser a consciência de sua própria humanidade e de sua essencial dignidade. Precedentes do STF” (BRASIL, 2000).

No julgado acima transcrito, já se começam a perceber elementos de um posicionamento político relevante por parte da Corte brasileira. Em primeiro lugar, ao classificar o direito à saúde como um direito público subjetivo, o STF, conforme critica José Reinaldo Lima Lopes (2006), está transformando a relação entre o cidadão e o Estado em uma relação entre credor e devedor. É que, ao afirmar que o direito à saúde é dever indissociável ao direito à vida, e que o Estado tem o "impostergável dever" de garantir esse direito de maneira quase absoluta, o que se está afirmando, na realidade, é que o Estado está em dívida para com seus cidadãos hipossuficientes, e que essa situação pode e deve ser resolvida por meio de uma ação judicial individual (e não apenas por meio da promoção de políticas públicas que tenham por escopo atingir diversos setores da população). 
Em segundo lugar, nota-se que o STF começa a julgar moralmente os poderes representativos, na medida em que afirma que eles não podem transformar uma norma constitucional em "mera promessa inconseqüente". Esse julgamento moral também transparece quando se fala em "infidelidade" do governo frente à Constituição, bem como quando se acusa os demais poderes de permanecerem indiferentes às necessidades da "população carente". Por fim, importa ainda sublinhar que a Suprema Corte posiciona-se de maneira abertamente favorável aos "menos favorecidos", o que fica particularmente claro quando se aduz que o Estado tem a obrigação de efetivar o direito à saúde "especialmente daquelas que nada têm e nada possuem, a não ser a consciência de sua própria humanidade e de sua essencial dignidade".

Ao longo da década de 2000, são proferidos diversos outros julgamentos, sempre com entendimento bastante similar ao anteriormente citado. Pode-se citar, a título de exemplo, os seguintes casos: Agravo Regimental no Recurso Extraordinário 393175/ RS, Rel. Min. Celso de Mello, julgado em 12/12/2006; Agravo Regimental no Agravo de Instrumento 553712/ RS, Rel. Min. Ricardo Lewandowski, julgado em 19/ 05/2009; Agravo Regimental na Suspensão de Tutela antecipada 17 / CE, Rel. Min. Gilmar Mendes, julgado em 17 de março de 2010; Agravo Regimental na Suspensão de Liminar SL 47/PE, Rel. Min. Gilmar Mendes, julgado em 17 de março de 2010.

Todas as decisões citadas até o momento favoreceram a concessão gratuita do medicamento ou do tratamento médico pleiteado. Por largo espaço de tempo, a tese da obrigatoriedade do fornecimento estatal de recursos destinados a garantir o direito à saúde foi praticamente absoluta. A partir de 2007, contudo, começam a surgir decisões que mobilizam outras categorias de argumentos, como o princípio da separação dos poderes e os limites orçamentários do Estado, indeferindo, a partir desses fundamentos, os pedidos judiciais que anteriormente eram concedidos sem maiores questionamentos.

Essa aparente modificação no entendimento do STF tem levado parte da literatura jurídica especializada a constatar a "insegurança jurídica" do cidadão que pleiteia remédios frente à Suprema Corte, uma vez que o atendimento ou não de seu pleito fica à mercê do ministro que vem a ser o responsável pelo caso. Nesse sentido, Wang (2009) parece dar a entender que o Supremo Tribunal Federal talvez esteja iniciando um período de transição no que diz respeito ao tratamento do tema, e que o consenso que antes existia acerca da necessidade de o poder Judiciário intervir na efetivação do direito à saúde não se faz mais presente na atualidade.
A proposição de Wang (idem) precisa, a nosso ver, ser relativizada. Em nosso entender, o STF continua fortemente favorável à intervenção judicial na política de distribuição de recursos da área da saúde, sendo que as decisões contrárias a esse entendimento, que começaram a surgir em 2007, são meras exceções ao posicionamento predominante, não havendo, portanto, indícios significativos de que está em curso uma inflexão na posição do Tribunal. $\mathrm{O}$ que se verifica, nesse sentido, é que o indeferimento da concessão judicial de medicamentos está ligado muitas vezes a questões processuais ou a probatórias ${ }^{8}$, sendo que o entendimento de fundo do Supremo Tribunal Federal continua sendo predominantemente favorável à tese de que é lícito ao poder Judiciário intervir em matéria de políticas distributivas. Entretanto, é necessário admitir que, antes de 2007, raramente uma demanda por medicamentos ou tratamentos médicos seria desatendida, ao passo que, atualmente, o indeferimento desse pleito é uma possibilidade, ainda que meramente excepcional.

Em outros termos, a hipótese defendida nesta seção é que o órgão de cúpula do poder Judiciário brasileiro, desde que se deparou com o tema pela primeira vez, tem sempre se mostrado favorável à necessidade de intervenção do Estado para assegurar condições mínimas de saúde aos cidadãos brasileiros hipossuficientes. As exceções a esse posicionamento não invalidam a tese geral.

Para corroborá-la, é relevante mencionar precedentes mais recentes do STF, bem como analisar mais detalhadamente os posicionamentos individuais de alguns ministros da Corte. Um importante argumento, inicialmente utilizado pelo Ministro Celso de Mello e reiterado em inúmeras decisões posteriores, aduz que, quando se trata de escolher entre uma prerrogativa econômico-orçamentária do Estado e o direito fundamental à vida e à saúde do indivíduo, deve o Supremo Tribunal Federal, por motivos de ordem moral, optar pelo segundo. Nas palavras do ministro: "Entre proteger a inviolabilidade do direito à vida, que se qualifica como direito subjetivo inalienável assegurado pela própria Constituição da República (art. $5^{\circ}$, caput), ou fazer prevalecer, contra essa prerrogativa

\footnotetext{
8 Por exemplo, no caso do Agravo Regimental na Suspensão de Tutela Antecipada 334/SC, Rel. Min. Cezar Peluzo, julgado em 24 de junho de 2010, o fornecimento de medicamento foi indeferido porque, segundo entendimento do relator do caso, a condição de portador de Hepatite $\mathrm{B}$ do demandante não restou devidamente comprovada, visto que o laudo médico constante nos autos não havia sido fornecido por médico cadastrado no sistema do Sistema Único de Saúde (SUS).
} 
fundamental, um interesse financeiro e secundário do Estado, entendo - uma vez configurado esse dilema que razões de ordem ético-jurídica impõem ao julgador uma só e possível opção: o respeito indeclinável à vida" (petição n. 1246, citada por Wang (2009, p. 281)).

Embora Celso de Mello seja, provavelmente, o ministro que mais entusiasticamente apóia a intervenção judicial para o fornecimento de medicamentos ou tratamentos médicos, ele certamente não é o único a adotar este posicionamento. Nesse mesmo sentido, Sidney Sanches afirmou que "em matéria tão relevante como a saúde descabem disputas menores sobre legislação, muito menos sobre verbas, questão de prioridade" (Trecho do RE 198263 RS, julgado em 30 de março de 2001, citado por Wang (ibidem)). Ainda, Ellen Greice afirmou que “obstáculos de ordem burocrática orçamentária [...] não podem ser entraves ao cumprimento constitucional que garante o direito à vida" (Trecho do RE 343413 MG, julgado em 26 de junho de 2002, citado por Wang (ibidem)), ao passo que Marco Aurélio ressaltou que "problemas orçamentários não podem obstaculizar o implemento do que previsto constitucionalmente" (Trecho do RE 195192 RS, julgado em 31 de março de 2000, citado por Wang (idem, p. 281)).

Dessa forma, questões orçamentárias, bem como o argumento da reserva do possível, não pareciam e não parecem fazer parte das principais preocupações do Supremo Tribunal Federal, pelo menos no que concerne às decisões que tratavam de fornecimento gratuito de medicamentos ou tratamentos médicos. É que, no entendimento do Tribunal, o direito à vida e o direito à saúde são inexoravelmente mais importantes do que quaisquer tipos de preocupações financeiras.

Conforme se adiantou, alguns autores ressaltaram que essa situação mudou, ainda que parcialmente, a partir do ano de 2007. A Ministra Ellen Greice protagonizou essa tentativa de mudança de entendimento, aparentemente contrariando o seu próprio posicionamento anterior. No julgamento monocrático da Suspensão de Segurança n. 3 073/ $\mathrm{RN}$, em 9 de fevereiro de 2007, a ministra reconheceu que a decisão liminar que determinava a obrigação do Estado do Rio Grande do Norte em fornecer medicamentos Mabithera (Rituximabe) + Chop para paciente portador de câncer causaria lesão à ordem pública, na medida em que abalaria a organização do sistema público de saúde. A ministra argumentou que "a gestão da política nacional de saúde, que é feita de forma regionalizada, busca uma maior racionalização entre o custo e o benefício dos tratamentos que devem ser fornecidos gratuitamente, a fim de atingir o maior número possível de beneficiários. Entendo que a norma do art. 196 da Constituição da República, que assegura o direito à saúde, refere-se, em princípio, à efetivação de políticas públicas que alcancem a população como um todo, assegurando-lhe acesso universal e igualitário, e não a situações individualizadas. A responsabilidade do Estado em fornecer os recursos necessários à reabilitação da saúde de seus cidadãos não pode vir a inviabilizar o sistema público de saúde. No presente caso, ao se conceder os efeitos da antecipação da tutela para determinar que o Estado forneça os medicamentos relacionados '[...] e outros medicamentos necessários para o tratamento [...]' (fl. 26) dos associados, estáse diminuindo a possibilidade de serem oferecidos serviços de saúde básicos ao restante da coletividade" (BRASIL, 2007).

A partir daí, a Ministra continuou lançando mão dos mesmos argumentos acima transcritos para indeferir o fornecimento de medicamentos e tratamentos médicos em alguns outros casos. No entanto, essa tentativa de inflexão não parece ter sido corroborada pelos demais ministros da Corte. Nesse sentido, uma análise cautelosa das decisões mais recentes do Supremo Tribunal Federal demonstra que, na realidade, os julgamentos da Ministra Ellen Greice, que negaram o fornecimento de medicamentos, são apenas exceções, sendo que a Corte como um todo parece seguir coerente na adoção de posicionamento favorável à concretização judicial do direito à saúde, uma vez que os julgamentos dos últimos três anos têm reiterado o tradicional entendimento da Corte. Com efeito, afirmou-se recentemente que "“a saúde é direito de todos e dever do Estado [...]", incumbindo a este viabilizar os tratamentos cabíveis" (BRASIL, 2011).

Em outros precedentes, a Corte tem reiterado que a mera alegação de que a concessão gratuita do medicamento pleiteado judicialmente causará "graves danos" aos cofres públicos não é suficiente para afastar a necessidade de concretização judicial do direito à saúde, sendo necessário, nesses casos, que o ente federativo demonstre efetivamente que tipo de prejuízo financeiro esse provimento judicial the acarretará ${ }^{9}$. Como esse tipo de prova é muito difícil de ser realizada, na prática a grande maioria dos pedidos de fornecimento de medicamentos continua sendo acatada pelo STF. Nesse sentido, frise-se que inclusive o financiamento de custosos tratamentos médicos têm sido chancelados pelo STF, como aconteceu no

\footnotetext{
9 Um exemplo desse entendimento pode ser verificado no julgamento do Agravo Regimental na Suspensão de Tutela Antecipada 361 AgR/BA, Rel. Min. Cezar Peluzo, julgado em 23 de junho de 2010.
} 
Recurso Extraordinário n. 368 564, Relator Ministro Marco Aurélio, julgado em 13 de abril de 2011, em que portadores de doença ocular progressiva lograram obter integral ressarcimento de despesas efetuadas com o tratamento de suas moléstias no exterior.

Reitera-se o ponto central da primeira parte deste trabalho: desde que se deparou inicialmente com o tema, o STF tem se inclinado fortemente no sentido de que o Estado deve fornecer gratuitamente medicamentos ou tratamentos médicos aos cidadãos carentes. Questões orçamentárias são, quando comparadas com o direito à vida e à saúde, quase que irrelevantes.

\section{CONCLUSÕES}

A análise da judicialização de políticas envolve um fenômeno que evidentemente transcende a esfera judicial. Engloba o ativismo de advogados, defensores públicos ou a mobilização dos agentes judiciais de um lado, assim como as dificuldades de afinidade entre princípios constitucionais relacionados a políticas sociais e a realidade das administrações municipais, estaduais e a administração federal.

Este trabalho procurou chamar a atenção para a importância das doutrinas jurídicas que fundamentam demandas judiciais e respostas do poder Judiciário em um caso representativo de ações que demandam políticas. Dimensão que em muitos trabalhos produzidos por juristas e cientistas políticos é dada como evidente. Ou seja, costuma-se tratar as diretrizes constitucionais e legais como se existissem independentemente da formação de consensos entre os juristas sobre a ação política.

Entendemos que o espaço possível das confrontações jurídicas é fortemente balizado pelas doutrinas jurídicas que contemplam definições do "papel do Estado" e do "interesse público". Nesse sentido, há uma agenda de pesquisa a ser explorada e que pode ser fortemente enriquecida com o crescimento de trabalhos que possam contribuir para melhor compreensão dos complexos mecanismos da legitimidade da intervenção do poder judicial na definição de políticas em regimes democráticos.

Fabiano Engelmann (fabengel@gmail.com) é Doutor em Ciência Política pela Universidade Federal do Rio Grande do Sul (UFRGS) e Professor do Departamento de Ciência Política da mesma universidade.

Marcio Camargo Cunha Filho (marciocunhafilho@yahoo.com.br) é Mestre em Ciência Política pela Universidade Federal do Rio Grande do Sul (UFRGS).

\section{REFERÊNCIAS BIBLIOGRAFICAS}

BARCELLOS, A. P. 2006. Constitucionalização das políticas públicas em matéria de direitos fundamentais: o controle político-social e o controle jurídico no espaço democrático. Revista de Direito do Estado, Rio de Janeiro, v. 3, n. 32.

. 2008. [AUTOR: ESTÁ FALTANDO O TÍTULO. Inserir em Times 11, sem itálico, negrito ou aspas]. In: SARLET, I. W. \& TIMM, L. B. 2008. (orgs.). Direitos fundamentais: orçamento e "reserva do possível". Porto Alegre: Livraria do Advogado.

BARROSO, L. R. 2009. Da falta de efetividade à judicialização efetiva: direito à saúde, fornecimento gratuito de medicamentos, e parâmetros para a atuação judicial. Revista de Direito Social, Rio de Janeiro, n. 34, p. 11-43. Disponível em: http:// download.rj.gov.br/documentos/10112/168750/ DLFE-29287.pdf/rev630402Dr.LuisRoberto Barroso.pdf. Acesso em: 12.abr.2013.

BARZOTTO, L. F. 2003. A democracia na Constituição. São Leopoldo: Unisinos.
BESERRA, F. H. 2005. Comentário sobre a decisão proferida na arguição por descumprimento de preceito fundamental $n^{\circ} 45 / \mathrm{DF}$. Revista de Direito Social, Rio de Janeiro, v. 5, n. 18, p. 99-110, abr.jun. Disponível em: http://tex.pro.br/tex/listagemde-artigos/229-artigos-jul-2005/5087-comentariosobre-a-decisao-proferida-no-julgamento-daargueicao-de-descumprimento-de-preceitofundamental-no-45df. Acesso em: 12.abr.2013.

BIEHL, J. 2009. Judicialização do direito à saúde no Brasil. In: KEINERT, T. M. M.; PAULA, S. H. B. \& BONFIM, J. R. A. (orgs.). As ações judiciais no SUS e a promoção do direito à saúde. São Paulo: Instituto de Saúde.

BRIQUET, J. L. 2001. La "guerre des justes". La magistrature antimafia dans la crise italienne In: BRIQUET, J. L. \& GARRAUD, P. Juger la politique. Rennes: Presses Universitaire de Rennes.

CHEVALIER, J. 1993. Le droit administratif en mutation. Paris: PUF. 
COMMAILLE, J.; DUMOULIN, L. \& ROBERT, C. (dirs.). 2000. La juridicisation du politique. Col. "Droit et société Classics". Paris: LGDJ.

COMMAILLE, J. \& DURAN, P. 2009. Pour une sociologie politique du droit. Présentation. L'Année Sociologique, Paris, v. 59, n. 1, numéro consacré à la sociologie politique du droit, p. 11-28.

COMMAILLE, J. \& KALUSZYNSKI, M. (dirs.). 2007. La fonction politique de la justice. Paris: La Découverte.

DEZALAY, Y. 1989. Marchands de droit: la restructuturation de l'ordre juridique international par les multinationales du droit. Paris: Fayard.

1993. La production doctrinale comme objet et terrain de luttes politique et professionnelles. In: BERNARD, A. \& POIRMEUR, Y. (dirs.). La doctrine juridique. Paris: PUF.

DWORKIN, R. 2005. A virtude soberana: a teoria e a prática da igualdade. São Paulo: M. Fontes.

ENGELMANN, F 2006. Sociologia do campo jurídico: juristas e usos do Direito. Porto Alegre: SAFE.

2008. Estudos no exterior e mediação de modelos institucionais: o caso dos juristas brasileiros. Revista de Sociologia e Política, Curitiba, v. 16, número suplementar, p. 145-157. Disponível em: http://www.scielo.br/pdf/rsocp/ v16s0/a11v16s0.pdf. Acesso em: 12.abr.2013.

EPP, C. 1998. The Rights Revolution: Lawyers, activists and Supreme Courts in comparative perspectives. Chicago: The University of Chicago.

FERRAZ, O. L. \& VIEIRA, F. S. 2009. Direito à saúde, recursos escassos e equidade: os riscos da interpretação judicial dominante. Dados, Rio de Janeiro, v. 52, n. 1, p. 223-251. Disponível em: http://www.scielo.br/pdf/dados/v52n 1/ v52n1a07.pdf. Acesso em: 12.abr.2013.

FRISCHEISEN, L. C. F. 2000. Políticas públicas: a responsabilidade do administrador e o Ministério Público. São Paulo: Max Limond.

GARRAUD, P. 2001. La politique à l'epreuve du jugement judiciaire. La pénalisation croissante du politique comme 'effet induit' du processus d'autonomisation de l'institution judiciaire In: BRIQUET, J. L. \& GARRAUD, P. Juger la politique. Rennes: Presses Universitaire de Rennes.

GOUVÊEA, M. M. 2003. O controle judicial das omissões administrativas. Rio de Janeiro: Forense.

ISRAEL, L. 2009. L'arme du droit. Paris: Presses de Science Po.
LOPES, J. R. L. 2006. Direitos sociais. Teoria e Prática. São Paulo: Academia do livro.

MCCANN, M. W. 2010. Poder Judiciário e mobilização do Direito: uma perspectiva dos usuários. Revista da EMARF, Cadernos Temáticos, Justiça Constitucional no Brasil: Política e Direito, Rio de Janeiro, p. 175-196, dez.

MENICUCCI, T. M. G. \& MACHADO, J. A. 2010. Judicialization of Health Policy in the Definition of Access to Public Goods: individual rights versus collective rights. Brazilian Science Political Review, São Paulo, v. 4, n. 1, p. 33-68. Disponível em: http://www.bpsr.org.br/english/arquivos/ BPSR_V4_n1_artigos/article_Menicuci Machado.pdf. Acesso em: 12.abr.2013.

NUNES JÚNIOR, V. S. 2009. A cidadania social na Constituição de 1988: estratégias de positivação e exigibilidade dos direitos sociais. São Paulo: Verbatim.

SOUZA NETO, C. P. \& SARMENTO, D. (orgs.). 2008. Direitos Sociais: fundamentos, judicialização e direitos sociais em espécie. Rio de Janeiro: Lumen Juris.

ROSENBERG, G. 2008. The Hollow Hope: Can courts bring about social change. $2^{\mathrm{a}}$ ed. Chicago: The University of Chicago.

ROUSSEL, V. 2002. Affaires de juges: les magistrats dans les scandales politiques en France. Paris: La Découverte.

SARAT, A. \& SCHEINGOLD, S. 1998. Cause Lawyering: Political commitments and professional responsibilities. New York: Oxford University.

2006. Cause Lawyer and Social Movements. Stanford: Stanford University.

SARLET, I. W. \& TIMM, L. B. (orgs.). 2008. Direitos fundamentais: orçamento e "reserva do possível". Porto Alegre: Livraria do Advogado.

SILVA, V. A. \& TERRAZAS, F. 2011. Claiming the right to health in Brazilian Courts: the exclusion of the already excluded? Law and Social Inquiry, Oxford, v. 36, n. 4, p. 825-853.

SHAPIRO, M. \& SWEET, A. S. 2002. On Law, Politics \& Judicialization. Oxford: Oxford University.

TAVARES, L. L. G. 2002. O fornecimento de medicamentos pelo Estado. Revista de Direito da Procuradoria-Geral, Rio de Janeiro, v. 55, p. 101111. Disponível em: http://download.rj.gov.br/ documentos/10112/777435/DLFE-46810.pdf/ 
Revista55Doutrina_pg_101_a_111.pdf. Acesso em: 12.abr.2013.

VAUCHEZ, A. 2009. Le pouvoir judiciaire. In: COHEN, A.; LACROIX, B. \& RIUTORT, P. (dirs.). Nouveau manuel de science politique. Paris: La Découverte.

WANG, D. W. L. 2009. Poder Judiciário e Políticas Públicas de Saúde: participação democrática e equidade. Cadernos Gestão Pública e Cidadania,
São Paulo, v. 54, p. 49-86. Disponível em: http:// www.eaesp.fgvsp.br/subportais/ceapg/Acervo\% 20Virtual/Cadernos/Cadernos/caderno\%2054\%20\%20final-2-07-05.pdf. Acesso em: 14.abr.2013.

WEBER, M. 1997. Economía y sociedad: esbozo de Sociologia Compreensiva. $11^{\mathrm{a}}$ ed. Ciudad de México: Fondo de Cultura Económica.

ZAGREBELSKY, G. 2008. El derecho dúctil: ley, derechos, justicia. $8^{a}$ ed. Madrid: Trotta.

\section{OUTRAS FONTES}

BRASIL. SUPREMO TRIBUNAL FEDERAL. 1999. Agravo Regimental no Agravo de Instrumento AI 238328/RS, Relator Min. Marco Aurélio, julgado em 16 de novembro.

.2000. Agravo Regimental no Recurso Extraordinário $271286 \mathrm{AgR} / \mathrm{RS}$, Relator Min. Celso de Mello, julgado em 12 de setembro.
2007. Ação de Suspensão de Segurança 3 274, julgada em 15 de agosto. Disponível em: http:// www.jusbrasil.com.br/jurisprudencia/19139337/ suspensao-de-seguranca-ss-3274-go-stf. Acesso em: 14.abr.2013.

2011. Recurso Extraordinário n. 368 564/DF, Rel. Min. Menezes Direito, Relatório para acórdão Min. Marco Aurélio, julgado em 13 de abril.

Anexo

PERFIL DETALHADO DAS DECISÕES

\begin{tabular}{|c|c|}
\hline Conteúdo da decisão & Argumento político \\
\hline $\begin{array}{l}\text { A orientação dessa Corte é tranqüila no sentido da viabilidade de deferir- } \\
\text { se o bloqueio de valores do Estado para aparelhar de maneira mais } \\
\text { efetiva o direto à saúde. Logo, torna-se desnecessária a condenação ao } \\
\text { pagamento de multa pelo não cumprimento de decisão de fornecer } \\
\text { medicamento. }\end{array}$ & $\begin{array}{l}\text { Tribunal opõe autoridade } \\
\text { do poder Judiciário à } \\
\text { autoridade do poder } \\
\text { Executivo na organização da } \\
\quad \text { gestão pública }\end{array}$ \\
\hline $\begin{array}{l}\text { O bloqueio de numerário é medida juridicamente cabível, diante da não } \\
\text { exaustividade do preceito legal citado e da finalidade da norma, tendo em } \\
\text { conta a necessidade de preservação da autoridade judiciária e em face } \\
\text { da gravidade dos bens que se busca preservar, ou seja, a saúde, que é } \\
\text { um direito fundamental. }\end{array}$ & $\begin{array}{l}\text { Tribunal opõe autoridade do } \\
\text { poder Judiciário à autoridade } \\
\text { do poder Executivo na } \\
\text { organização da gestão } \\
\text { pública }\end{array}$ \\
\hline $\begin{array}{l}\text { O pedido administrativo apesar de ser um expediente útil ao ente público } \\
\text { e aos próprios cidadãos é uma formalidade burocrática e sua não } \\
\text { observância não pode ser óbice a impedir o requerimento judicial de } \\
\text { fornecimento do medicamento de que necessita o autor. }\end{array}$ & $\begin{array}{l}\text { Tribunal opõe autoridade do } \\
\text { poder Judiciário à autoridade } \\
\text { do poder Executivo na orga- } \\
\text { nização da gestão pública }\end{array}$ \\
\hline $\begin{array}{l}\text { Também é possível, não estando, por algum motivo, disponível o } \\
\text { medicamento, ordenar-se ao Poder Público a entrega de dinheiro } \\
\text { equivalente, a fim de que o necessitado possa comprá-lo no comércio } \\
\text { privado. A não ser assim, frustra-se a garantia constitucional da assistência } \\
\text { à saúde. }\end{array}$ & $\begin{array}{l}\text { Tribunal opõe autoridade do } \\
\text { poder Judiciário à autoridade } \\
\text { do poder Executivo na } \\
\text { organização da gestão } \\
\text { pública }\end{array}$ \\
\hline $\begin{array}{l}\text { O fato de o medicamento, receitado pelo médico do necessitado, como } \\
\text { sendo o mais adequado e eficiente para o caso específico, não ser liberado } \\
\text { pelo Ministério da Saúde (não constar na Lista da ANVISA), ou, mesmo, } \\
\text { só existir no mercado internacional, não isenta o Poder Público de cobrir } \\
\text { o custo. }\end{array}$ & $\begin{array}{l}\text { Tribunal opõe autoridade do } \\
\text { poder Judiciário à autoridade } \\
\text { do poder Executivo na } \\
\text { organização da gestão } \\
\text { pública }\end{array}$ \\
\hline $\begin{array}{l}\text { Teoria do possível ou da reserva do possível. O art. } 196 \text { da CF não traduz } \\
\text { norma não autoaplicável, e sim norma programática, isto é, o Constituinte } \\
\text { delegou ao intérprete a missão de revelá-lo, em termos qualitativos e } \\
\text { quantitativos, no mundo dos fatos, conforme as novas verdades sociais. }\end{array}$ & $\begin{array}{l}\text { Tribunal opõe autoridade do } \\
\text { poder Judiciário à autoridade } \\
\text { do poder Executivo na orga- } \\
\text { nização da gestão pública }\end{array}$ \\
\hline
\end{tabular}


Ainda que se considere que o direito de acesso à saúde esteja condicionado ao estabelecimento de políticas públicas que garantam acesso universal e igualitário, o exame da suficiência da política pública incumbe ao Poder Judiciário, como forma de assegurar o conteúdo mínimo de proteção, exigido pelo princípio constante no direito fundamental de acesso à saúde.

Ao poder Judiciário cabe dar efetividade à lei. Ou seja, se a lei não for observada, ou for desrespeitada pelo poderes públicos, o Judiciário é chamado a intervir e dar resposta efetiva às pretensões das partes.

Condenação dos entes estatais ao atendimento de direito fundamental à saúde não fere o princípio de divisão dos poderes.

Acesso à saúde é direito constitucional.

O direito à assistência à saúde emana diretamente de norma constitucional e significa atendimento integral, quer dizer, abrange tanto ações curativas quanto preventivas.

A dignidade da pessoa humana é um dos fundamentos da República (CF, art. $\left.1^{\circ}, \mathrm{III}\right)$. Ainda, se o direito emana diretamente da Constituição, deve ser observado e garantido. Não há falar em artifícios outros, como a ingerência do poder Judiciário no poder Executivo, princípio da igualdade, questões orçamentárias e concessão de crédito.

Entes estatais são solidariamente responsáveis pelo adimplemento dos direitos fundamentais.

conste em sua lista de competência.

Município é parte legitima para prover direito à saúde mesmo que não

O interesse de agir, que decorre da necessidade de acesso ao poder Judiciário para obtenção do bem da vida, dispensa prévio recurso à via administrativa.

A desejável organização interna dos serviços, com a distribuição de competência para a gestão da saúde pública, não deve atingir o direito de o particular exigir a devida prestação dos serviços de saúde de quaisquer dos entes federados.

Saliente-se que a distribuição de competência dentro do Sistema Único de Saúde (Lei n. 8 080/90) não tem o condão de afastar a responsabilidade solidária dos entes públicos.

O poder Judiciário não é insensível aos graves e agudos problemas financeiros por que passam os entes federativos. Entretanto, ao poder Judiciário cabe dar efetividade à lei.
Tribunal opõe autoridade do Judiciário à autoridade do poder Executivo na organização da gestão pública

Tribunal opõe autoridade do poder Judiciário à autoridade do poder Executivo na organização da gestão pública

Tribunal interpreta sentido do princípio da divisão dos 2 poderes

Tribunal guardião da Constituição

Tribunal guardião da Constituição

Tribunal guardião da Constituição

Unidade do "Estado" para garantir direito fundamental superpõem-se à princípio federativo

Unidade do "Estado" para garantir direito fundamental superpõem-se à normas administrativas da gestão de políticas

Unidade do "Estado" para garantir direito fundamental superpõem-se à normas 4 administrativas da gestão de políticas

Unidade do "Estado" para garantir direito fundamental superpõem-se à normas 4 administrativas da gestão de políticas

Unidade do "Estado" para garantir direito fundamental superpõem-se à normas 4 administrativas da gestão de políticas

Tribunal define que efetividade do direito é superior à gestão orçamentária e discussão doutrinária da "reserva do possível" 
Não se alegue que o princípio da reserva do possível - com base em normas orçamentárias restritivas - é limitador da atuação da Administração no caso concreto.
Tribunal define que efetividade do direito é superior à gestão orçamentária e 5 discussão doutrinária da "reserva do possível"

É obrigação do Poder Público a destinação de verbas orçamentárias à saúde, razão pela qual não há falar em programas não incluídos na lei orçamentária anual e transposição ou transferência de recursos de uma categoria de programação para outra ou de um órgão para outro.
Tribunal define que efetividade do direito é superior à gestão orçamentária e discussão doutrinária da "reserva do possível

Falta de previsão orçamentária do Estado para efetivar direito à saúde é descaso do administrador com a população e a ordem constitucional.

Tribunal julga moralmente o poder Executivo

Os maus antecedentes do Poder Público em relação ao dever de prestar assistência à saúde, por si só afirmam presunção de interesse processual $\left(\mathrm{CPC}\right.$, art. $\left.3^{\circ}\right)$, isto é, necessidade de intervenção do poder Judiciário.

Tribunal julga moralmente 0 poder Executivo

O direito de acesso à saúde pode ser exercido pelo cidadão frente ao Estado, dele exigindo a prestação de políticas públicas e também sua correção ou complementação se insuficientes ou ineficazes aos seus fins.

Tribunal julga moralmente o poder Executivo

\section{Anexo 2}

\section{TRABALHOS DE DOUTRINA JURÍDICA SOBRE POLÍTICAS-PÚBLICAS ANALISADOS}

AMARAL, G. 2010. Direito, escassez e escolha. Rio de Janeiro: Lumen Juris.

BARCELOS, A. P. 2002. A eficácia jurídica dos principios constitucionais. Rio de Janeiro: Renovar.

BARROSO, L. R. 2005. Neoconstitucionalismo e constitucionalização do Direito. Revista de Direito Administrativo, Rio de Janeiro, v. 240, p. 1-42.

. 2009. Da falta de efetividade à judicialização excessiva: Direito à saúde, fornecimento gratuito de medicamentos e parâmetros para a atuação judicial. Revista de Direito Social, Rio de Janeiro, v. 34 , p. 11-43.

.2009. O direito constitucional e a efetividade de suas normas. Rio de Janeiro: Renovar.

BLIACHERIENE, A. C. \& SANTOS, J. S. 2010. Direito à vida e à saúde: impactos orçamentário $\mathrm{e}$ judicial. São Paulo: Atlas.

COUTINHO, D. R. \& VOJVODIC, A. M. 2009. Jurisprudência constitucional: como decide o STF? São Paulo: Malheiros.

DIAS, J. C. 2007. Controle jurisdicional de políticas públicas. São Paulo: Método.

FIGUEIREDO, I. 2006. Políticas públicas e a realização dos direitos sociais. Porto Alegre: Sérgio Antonio Fabris.
GALDINO, F. 2005. Introdução à teoria dos custos do direito - direitos não nascem em árvores. Rio de Janeiro: Lumen Juris.

GAURI, V. 2004. Social Rights and Economics: Claims to health care and education in developing countries. World Development, Kidlington, v. 32, n. 3, p. 465.

HOLMES, S. \& SUNSTEIN, C. R. 1999. The Cost of Rights. New York: Norton.

KELBERT, F. O. 2011. Reserva do possivel e a efetividade dos direitos sociais no Direito brasileiro. Porto Alegre: Livraria do Advogado.

LOPES, J. R. L. 2006. Direitos Sociais: teoria e prática. São Paulo: Método.

. 1994. Judiciário, Democracia, políticas públicas. Revista de Informação Legislativa, Brasília, v. 31, n. 22, p. 255-265, maio.

MEIRELES, H. L. 2011. Direito administrativo brasileiro. $21^{a}$ ed. São Paulo: Malheiros.

MELLO, C. A. B. 2009. Eficácia das normas constitucionais e direitos sociais. São Paulo: Malheiros.

OLSEN, A. C. L. 2008. Direitos fundamentais sociais: efetividade frente à reserva do possível. Curitiba: Juruá.

SARLET, I. W. 2009. A eficácia dos direitos fundamentais. $10^{\mathrm{a}}$ ed. Porto Alegre: Advogado. 
SILVA, J. A. 1999. Aplicabilidade das normas constitucionais. $3^{\text {a }}$ ed. São Paulo: Malheiros.

Direitos Fundamentais: conteúdo essencial. $2^{\mathrm{a}}$ ed. São Paulo: Malheiros.
TORRES, R. L. 2009. Direito a um mínimo existencial. Rio de Janeiro: Renovar. 